\title{
PERFORMANCE OF THE FAHY SIMPLEX PERMEAMETER
}

\author{
By Raymond L. Sanford
}

\section{ABSTRACT}

This report gives the results of a test of the Fahy Simplex permeameter which has come into quite general use for magnetic testing. The magnetic standards employed had previously been found to be sufficiently uniform to give results in the Burrows permeameter estimated to be accurate within less than 1 per cent. The experimental results indicate that the Simplex instrument is accurate within about 2 per cent with uniform bars, and that it gives more consistent and apparently more reliable results for nonuniform specimens than does the Burrows permeameter.

\section{CONTENTS}

I. Introduction

II. Description of the instrument

III. Observations and results

1. Accuracy under normal conditions

2. Effect of length of specimen

3. Effect of area of specimen

4. Effect of contact reluctance

5. Effect of nonuniformity in specimen

6. Hysteresis determinations

\section{INTRODUĆTION}

From the standpoint of simplicity and convenience of operation, the Fahy Simplex permeameter has certain advantages over other ballistic methods for magnetic testing, and its use has become quite general. Several years ago this instrument was adopted by the Bureau of Standards for routine testing. The decision was based primarily on statistical evidence collected during a period of about five years which indicated that, on the average, the Simplex is in satisfactory agreement with the Burrows permeameter, which has long been accepted as standard. Moreover, it seemed probable that the Simplex was more apt to give a good indication of the average properties of a nonuniform test bar than the Burrows permeameter, which is particularly sensitive to the effect of nonuniformity.

The desirability of a more definite and conclusive check on the accuracy of the Simplex instrument has been fully realized from the beginning, and experimental work has been in more or less continuous progress for several years. The only conclusion that could be drawn from most of the results, however, was that although the two methods generally do not agree, the differences are not consistent either in sign or magnitude. The source of the discrepancy was finally traced to the influence of nonuniformity in the specimens to which the Burrows permeameter is particularly sensitive. The check on 
the Simplex was, therefore, deferred until more satisfactory standards could be obtained. As the result of the work on this phase of the problem, which has been described in a previous paper, ${ }^{1}$ four magnetic standards of satisfactory quality were obtained. Although it would be better to have a larger number of standards covering a greater range of permeability, it was felt that tests even with this limited number should be undertaken at once. The results of the tests, which are here reported, justify the continued use of the Simplex permeameter for general magnetic testing.

\section{DESCRIPTION OF THE INSTRUMENT}

The Fahy Simplex permeameter ${ }^{2}$ consists essentially of a laminated electromagnet, across the poles of which the specimen is clamped, together with test coils for the measurement of magnetizing force and magnetic induction. The instrument, with a specimen clamped in place, is shown in Figure 1.

The test coil for measuring the induction is wound uniformly on a brass form, split to avoid the effect of eddy currents, which extends over the whole length of the specimen included between the pole pieces. When this coil is connected with the galvanometer the deflection upon reversal of current in the winding of the electromagnet is proportional to the magnetic induction in the specimen. Suitable corrections are made for the flux in the air space between the specimen and the test coil.

The magnetizing force is determined by means of another test coil of many turns uniformly wound on a nonmagnetic form which extends between two soft iron blocks. These iron blocks are clamped against the ends of the specimen opposite the pole pieces. When this coil is connected to the galvanometer, the deflection upon reversal of the magnetizing current is proportional to the difference of magnetic potential between its ends. The iron blocks serve in effect to transfer the ends of the coil to the ends of the specimen so that the deflection is proportional to the average magnetizing force acting over the whole length of the test bar. The small error due to the reluctance of the iron blocks and leakage from the ends of the specimen is corrected by using a constant for this $\mathrm{H}$ coil slightly different from the experimentally determined value. The proper constant to use is specified by the maker.

The usual switches and rheostats are employed to control the magnetizing current, and the galvanometer is calibrated by means of a standard mutual inductor in the regular way.

\section{OBSERVATIONS AND RESULTS}

Experience with the Simplex permeameter over a period of several years has shown that the apparatus gives consistent and reproducible results. It is always possible to check results on a retest within the allowable experimental error. In checking the performance of the apparatus, the accuracy of measurement was first determined by using the standard bars under normal conditions. These bars had

1 Sanford, Standards for Testing Magnetic Permeameters, B. S. Jour. Research, 4 (RP140), p. 177; February, 1930.

2 Fahy, Chem. and Met. Eng., 19, p. 339; 1918. 
B. S. Journal of Research. RPI74

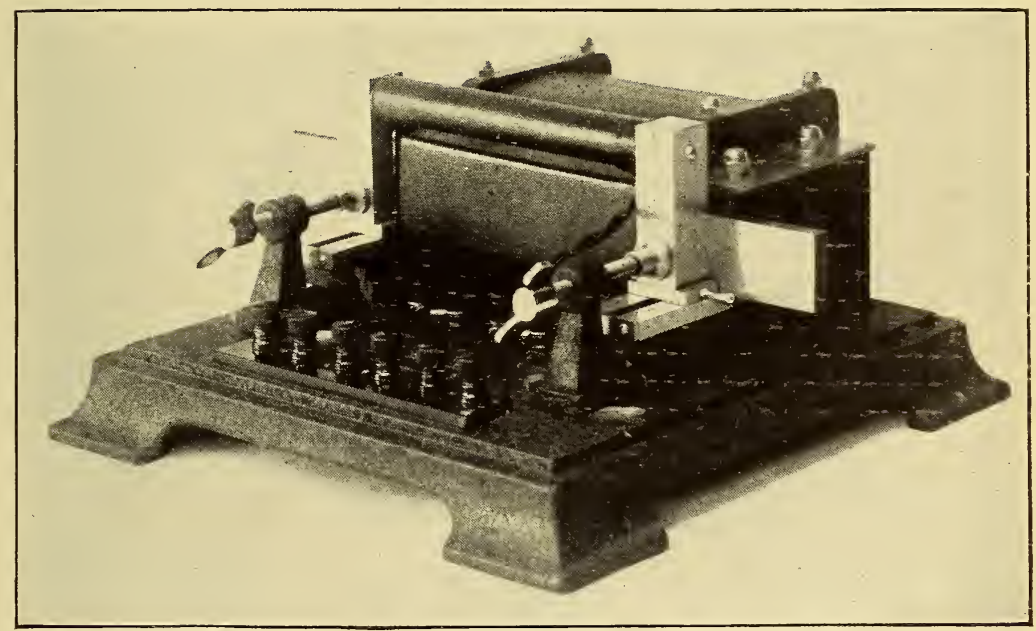

Figure 1.-The Fahy Simplex permeameter 
been previously calibrated by testing with the Burrows permeameter, whose accuracy with uniform bars is well within 1 per cent. Determinations were then made of the influence of various factors which might affect the accuracy. The following factors were considered: Length of the specimen, area of the specimen, variations in contact reluctance, and nonuniformity of the specimen. The use of this method for testing laminated specimens of sheet material has already been investigated. ${ }^{3}$ A check was also made of the accuracy of hysteresis determinations.

\section{ACCURACY UNDER NORMAL CONDITIONS}

The results of the test under normal conditions are shown graphically in the curves of Figure 2. The majority of the points obtained fall upon the Burrows curves well within the experimental error, differences rarely exceeding 2 per cent excepting at low values of induction where the precision of reading is necessarily low. The maximum permeability of the standards ranges from 375 for No. 290 to 1,950 for $\mathrm{A}-32$. This covers the range of values met with in ordinary testing very well except, perhaps, in the cases of magnet steel and electrical sheet. Bar No. 290, however, is not much higher in permeability than tungsten or chromium magnet steels. The results of the previously published investigation ${ }^{4}$ showed that a similar degree of accuracy is obtained with laminated specimens having permeabilities as high as 6,000 provided that the sample consists of not more than 15 strips having a width of not less than $3 \mathrm{~cm}$. Thus it would appear that under normal testing conditions the Fahy Simplex permeameter gives an accuracy comparable with that of the Burrows method which is estimated to be well within 1 per cent.

\section{EFFECT OF LENGTH OF SPECIMEN}

One factor which might be expected to affect the accuracy of the Simplex apparatus is the length of the specimen. If there is an appreciable projection beyond the pole pieces, it might be expected that there would be a direct reaction on the coil used for measuring magnetizing force. This point was investigated by making tests with a bar which projected beyond the poles approximately $10 \mathrm{~cm}$ at either end. No appreciable difference was found when the bar was again tested after cutting off the projecting ends.

\section{EFFECT OF AREA OF SPECIMEN}

No positive test could be made on the effect of area alone. It might appear feasible to take a bar having the maximum cross section for which the apparatus is adapted and machine it to various smaller sizes, comparing the results of tests made for each area. This is not a safe practice, however, as machining inevitably introduces a certain degree of mechanical strain which has a relatively large effect on the magnetic properties. Comparison with the Burrows using a bar machined to successively smaller and smaller areas was not feasible because no bar sufficiently uniform for the purpose was available. The

${ }^{3}$ Sanford and Barry, Determinations of the Magnetic Induction in Sheet Steel, B. S. Sci. Papers, 21, p. $757 ; 1927$.

See footnote 3 


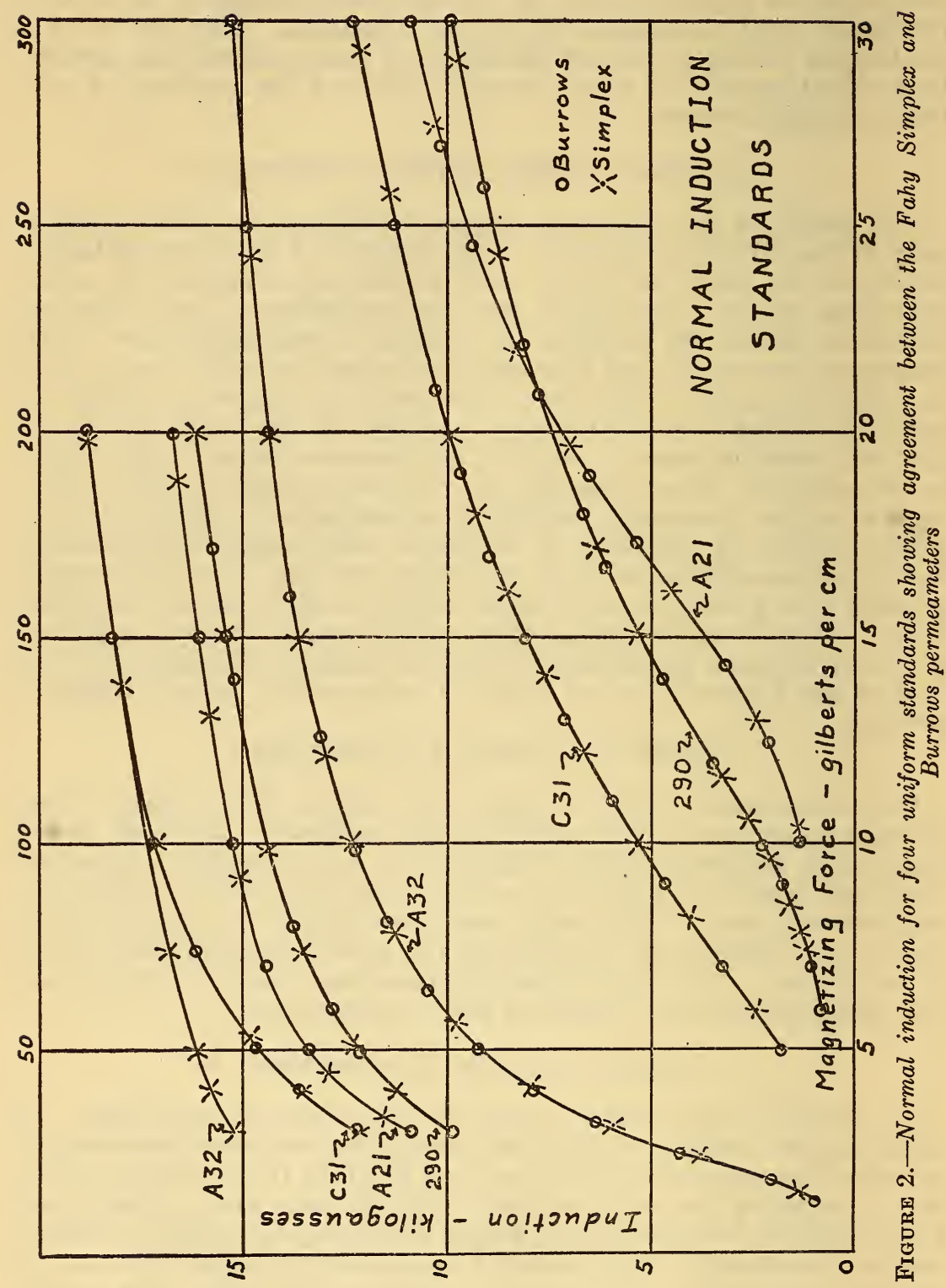




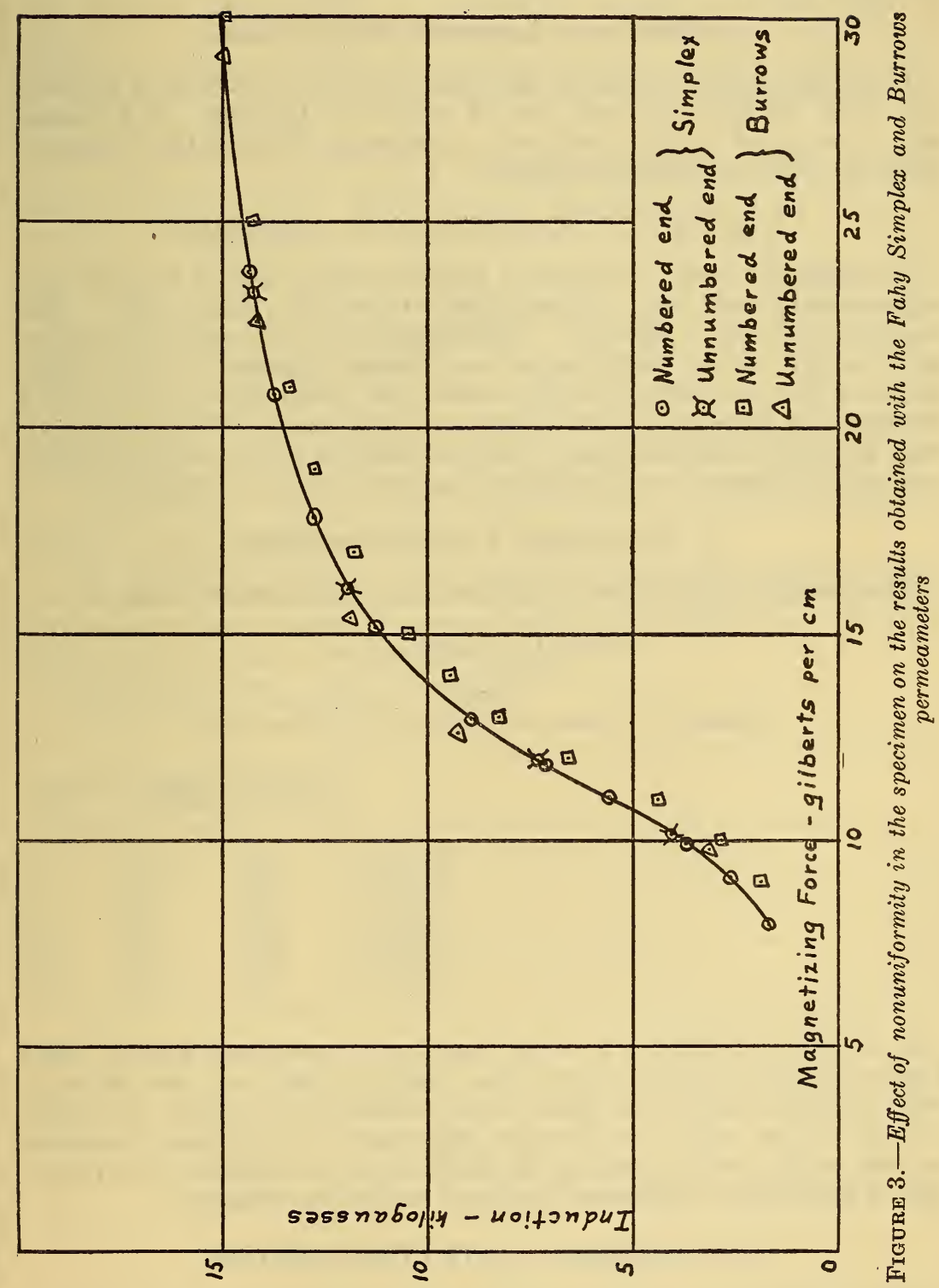


effect within the range of areas represented by the standards, however, is negligible. The areas range from $1.00 \mathrm{~cm}^{2}$ to $1.92 \mathrm{~cm}^{2}$. This covers the values ordinarily met with and it seems reasonable to assume that any appreciable effect due to area would be noticed in this variation of nearly 2 to 1 .

\section{EFFECT OF CONTACT RELUCTANCE}

If the iron blocks at the ends of the $\mathrm{H}$ coil do not make good contact with the test specimen, the $\mathrm{H}$ values are too low. If a reasonable amount of care is exercised in adjusting the contact pressure, however, little trouble will be had.

\section{EFFECT OF NONUNIFORMITY IN SPECIMEN}

In order to check this point, a test was made with a bar having a magnetically hard spot approximately $6 \mathrm{~cm}$ from the middle. The results are shown in Figure 3. The change in the location of the hard spot within the test coils makes very little difference in the indications of the Simplex, although with the Burrows permeameter a variation of approximately 20 per cent was noted. This would appear to justify the conclusion that the Simplex gives more consistent and reliable results on nonuniform bars than does the Burrows.

\section{HYSTERESIS DETERMINATIONS}

The results of hysteresis determinations are given in Table 1.

TABLE 1.-Hysteresis data

$H_{\max }=200$

[Inductions in kilogausses; magnetizing forces in gilberts per $\mathrm{cm}$ ]

\begin{tabular}{|c|c|c|c|c|}
\hline 1 & & $\begin{array}{l}\text { Maximum } \\
\text { induction }\end{array}$ & $\begin{array}{c}\text { Residual } \\
\text { induction }\end{array}$ & $\begin{array}{l}\text { Coercive } \\
\text { force }\end{array}$ \\
\hline A 32. & $\left\{\begin{array}{l}\text { Standard } \\
\text { Stannar }\end{array}\right.$ & 18.83 & 10. 70 & 2.6 \\
\hline C 31 & Standard. & 18. 99 & 7.60 & 7.2 \\
\hline 290 & \{Standard.. & 16.09 & 8.75 & 12.5 \\
\hline & Standard.- & $\begin{array}{l}16.19 \\
16.70\end{array}$ & $\begin{array}{r}8.75 \\
12.25\end{array}$ & $\begin{array}{l}12.5 \\
16.6\end{array}$ \\
\hline A 21 & $\{$ Simplex & 16.68 & 12.00 & 16.7 \\
\hline
\end{tabular}

It would be desirable to make tests with specimens having much higher values of coercive force, but, unfortunately, no bars of hardened magnet steel have been found sufficiently uniform to obtain reliable values with the Burrows apparatus. In general, however, in view of the results given in the table, it seems reasonable to expect that a satisfactory degree of accuracy would be obtained.

\section{SUMMARY AND CONCLUSIONS}

The increasing use of the Fahy Simplex permeameter for magnetic testing is due, for the most part, to its simplicity and ease of operation. There has been some uncertainty as to its accuracy, because the results of tests made with this instrument generally do not agree with those made on the same specimen with the Burrows permeameter which for 
many years has been accepted as standard. There is, however, no systematic difference, and the Bureau of Standards, some years ago, adopted the Simplex instrument for routine magnetic testing.

The principal source of discrepancy lies in the inhomogeneity almost invariably found in magnetic test specimens. In view of the fact that the Burrows permeameter is exceedingly sensitive to the effect of magnetic nonuniformity in the specimen, it is not fair to conclude that differences between the Burrows permeameter and any other testing method are errors in the other method unless the test specimens are known to be uniform.

Tests under normal conditions, using as magnetic standards specimens which have been checked for uniformity and found to be satisfactory, show that the Fahy Simplex permeameter gives values of induction corresponding to given values of magnetizing force which are accurate within 2 per cent and that a comparable degree of accuracy is obtained in hysteresis determinations. So far as there is evidence available, this holds throughout the range of cross sections for which the instrument is adapted. With reasonable care in clamping, there is no appreciable error due to contact reluctance. Also, projection of the specimen beyond the apparatus does not introduce appreciable errors. For nonuniform specimens, the results with the Simplex instrument are more consistent and probably represent the average properties of the material better than those obtained with the Burrows permeameter.

These results confirm those previously obtained with sheet steel and lead to the conclusion that the continued use of the Fahy Simplex permeameter for routine magnetic testing is justified and that the instrument is suitable for general testing.

Washington, December 5, 1929. 